\title{
ANÁLISE DE CONFIABILIDADE PARA FORMULAÇÃO DE ESTRATÉGIA DE MANUTENÇÃO DE EQUIPAMENTOS EM UMA EMPRESA DA INDÚSTRIA ALIMENTÍCIA
}

\section{RELIABILITY ANALYSIS FOR EQUIPMENT MAINTENANCE STRATEGY DEFINITION IN A FOOD INDUSTRY COMPANY}

\author{
Denis Komninakis* E-mail: denis komninakis@yahoo.com.br \\ Claudio Luis Piratelli* E-mail: clpiratelli@uniara.com.br \\ Jorge Alberto Achcar** E-mail: achcar@fmrp.usp.br \\ *Universidade de Araraquara (UNIARA), Araraquara, SP \\ ** Universidade de São Paulo (USP), São Paulo, SP
}

Resumo: A função manutenção tem um importante papel na busca por vantagens competitivas pelas empresas. Nesse sentido, a análise de confiabilidade de equipamentos é parte fundamental para a definição e seleção de estratégias de manutenção mais adequadas. $O$ objetivo deste trabalho é avaliar, por meio de análise de confiabilidade, a coerência da atual estratégia de manutenção de equipamentos de uma empresa da indústria alimentícia localizada no interior do Estado de São Paulo. O método de pesquisa utilizado foi a modelagem estatística aplicada ao tempo de reparo (TTR) e tempo entre falhas (TBF) de um conjunto de 6 máquinas de embalagem de uma das linhas de produção. Estes tempos foram modelados por distribuições de probabilidade Log-normal e Weibull. Os resultados apontam que a atual estratégia de manutenção preventiva adotada para os equipamentos não está adequada, pois os equipamentos se encontram na fase de mortalidade infantil do ciclo de sua vida útil, o que sugere o emprego da estratégia de manutenção corretiva com o objetivo de se identificar e eliminar as falhas de origem.

Palavras-chave: Análise de Confiabilidade. Estratégia de Manutenção. Disponibilidade. Indústria Alimentícia.

\begin{abstract}
Maintenance plays an important role in the pursuit of competitive advantages by companies. Equipment reliability analysis is in this regard essential in defining the most appropriate maintenance strategies. This study applies reliability analysis to evaluate the coherence of the current equipment maintenance strategy employed in a Brazilian food industry company in São Paulo state. The research method used was statistical modeling applied to the time to repair (TTR) and time between failures (TBF) for six packaging machines on one of the company's production lines. These times were modeled by Log-normal and Weibull probability distributions. The results indicate that the current preventive maintenance strategy adopted for the equipment is not appropriate, as the equipment is in the infant mortality phase in the cycle of its working life, which indicates a corrective maintenance strategy be used to identify and eliminate the origin faults.
\end{abstract}

Keywords: Reliability Analysis. Maintenance Strategy. Availability. Food Industry.

\section{INTRODUÇÃO}

A busca por "vantagens competitivas" tem sido uma das mais importantes 
metas administrativas e gerenciais de empresas por todo o mundo (VACCARO, 1997).

Como estratégia de competitividade empresarial, a gestão da manutenção tem se mostrado um fator extremamente relevante, visto que a produtividade está diretamente relacionada à redução dos custos e pode propiciar aumento do faturamento. Melhorias na confiabilidade e na disponibilidade dos equipamentos produtivos podem contribuir significativamente para aumentar a competitividade das organizações (SELLITTO; BORCHARDT; ARAUJO, 2002).

Tradicionalmente, a manutenção não é planejada com base em dados reais, mas realizada a partir da experiência dos funcionários envolvidos, orientados pelos manuais dos fabricantes. A fim de maximizar a venda de componentes ou minimizar responsabilidades, alguns fabricantes orientam intervalos curtos de revisão e substituição de partes e componentes (MENDES; RIBEIRO, 2011; RAUSAND, 1998).

Para Farrero, Tarrés e Losilla (2002), a otimização da política de manutenção requer uma combinação balanceada entre manutenções preventivas, preditivas e corretivas, sendo que o tipo de manutenção e o intervalo entre manutenções de cada item depende do comportamento de sua taxa de falhas e do custo de cada falha.

Para Sellitto (2007), o uso da metodologia RCM (Reliability-Centered Maintenance - Manutenção Centrada na Confiabilidade) é importante para a definição de estratégias de manutenção que objetivam aumentar a confiabilidade e a disponibilidade de equipamentos.

A elaboração de planos de manutenção baseados em análises quantitativas é essencial para a compreensão do tipo e do intervalo de manutenção mais adequado ao comportamento da taxa de falhas de cada equipamento, permitindo assim, formular a melhor estratégia de manutenção para cada equipamento, evitando a execução de atividades desnecessárias ou ineficazes de manutenção (MENDES; RIBEIRO, 2014; SANTOS; SELLITTO, 2016).

Nesse sentido, Sellitto $(2005,2007)$ e Mengue e Sellitto (2013) definem, a partir de funções de confiabilidade, estratégias de manutenção em indústrias metalmecânica baseadas no comportamento da taxa de falhas dos equipamentos. Utilizam a curva da banheira como uma forma genérica de visualização gráfica da 
função taxa de falha que identifica o ciclo de vida de um item: mortalidade infantil, maturidade e fase de desgaste (KLUTKE; KIESSLER; WORTMAN, 2003).

O foco deste estudo é uma empresa do setor de alimentos que adota, atualmente, uma estratégia de manutenção preventiva com paradas mensais para todos os equipamentos produtivos. A questão da pesquisa a ser respondida é: a partir dos trabalhos de Sellitto $(2005,2007)$ e Mengue e Sellitto (2013), a definição da atual estratégia de manutenção da empresa objeto de estudo é a mais adequada para seus equipamentos produtivos?

O objetivo desta pesquisa é avaliar a coerência da definição da atual estratégia de manutenção para os equipamentos produtivos em uma empresa da indústria alimentícia por meio do uso de funções de confiabilidade.

Esta pesquisa é de natureza aplicada, de abordagem quantitativa e, como método, utiliza a modelagem estatística com o objetivo de calcular a confiabilidade de equipamentos por meio do modelamento do tempo entre falhas - TBF e do tempo de reparo - TTR dos equipamentos utilizados exclusivamente na produção.

Equipamentos operando fora de suas condições ótimas podem gerar perdas irrecuperáveis para empresas inseridas em mercados competitivos. Além disso, em geral, o investimento em um equipamento de produção é elevado, razão pela qual se deve buscar maximizar sua utilização e, consequentemente, aumentar o seu retorno financeiro para a organização (MENGUE; SELLITTO, 2013; RAPOSO, 2011).

O artigo está estruturado da seguinte forma:

$\mathrm{Na}$ seção 2 são apresentados alguns fundamentos de confiabilidade, mantenabilidade e disponibilidade aplicados à manutenção industrial.

A seção 3 apresenta a abordagem metodológica e classificação da pesquisa quanto ao método científico, os procedimentos operacionais e a caracterização da empresa objeto de estudo.

Na seção 4 encontra-se a seleção da amostra dos equipamentos estudados, a modelagem estatística da confiabilidade e os principais resultados.

$\mathrm{Na}$ seção 5 se discute os resultados da pesquisa em função da questão de pesquisa. Em outras palavras, para fins de gestão da manutenção, compara-se a atual estratégia de manutenção da empresa objeto de estudo com a estratégia de manutenção recomendada a partir dos resultados da modelagem. 
Por fim, na seção 6 se encontram as conclusões, considerações finais e propostas de trabalhos futuros.

\section{CONFIABILIDADE, MANTENABILIDADE E DISPONIBILIDADE NA MANUTENÇÃO INDUSTRIAL}

Confiabilidade, mantenabilidade e disponibilidade são fatores cruciais para o sucesso das empresas. Altos custos motivam a busca por soluções de engenharia que aumentem a confiabilidade, reduzam gastos financeiros e aumentem a satisfação dos clientes com entregas pontuais por meio de uma maior disponibilidade dos equipamentos.

Segundo Ebeling (1997), pode-se definir confiabilidade como a probabilidade de um componente ou sistema funcionar durante um determinado período de tempo, quando usado sob certas condições operacionais.

A percepção de confiabilidade vem mudando ao longo do tempo. Enquanto nas décadas de 1960 e 1970 era uma unidade discreta na matriz organizacional, atualmente é parte integral do time de engenharia (IRESON; COOMBS; MOSS, 1995).

Para Rausand e Oien (1996) e Vaz (2003), falha é o término da capacidade total ou parcial de uma peça, componente, equipamento ou sistema em desempenhar sua função durante um período de tempo. Um erro não é uma falha, pois ele possui um limite aceitável de desvio em relação à sua performance esperada (valor alvo).

\subsection{Modelos de Funções de Confiabilidade}

Para Vaccaro (1997), por meio de um conjunto de Funções de Confiabilidade, torna-se possível uma descrição do comportamento da confiabilidade de um produto, peça, componente ou sistema.

A função de confiabilidade $R(t)$ - também denominada de função sobrevivência $S(\mathrm{t})$ - é uma das principais funções probabilísticas usadas para descrever estudos de sobrevivência e, é definida como a probabilidade de uma observação não falhar até um certo tempo $t$. Por meio da $R(t)$ é possível determinar 
a probabilidade de sucessos de não falhas durante um tempo determinado (COLOSIMO; GIOLO, 2006; KECECIOGLU, 2002a).

A função densidade de probabilidade de falha, denotada por $f(t)$, permite determinar as probabilidades de falhas ao longo de um período de tempo (KECECIOGLU, 2002a).

A função taxa de risco ou taxa de falha, denotada por $h(t)$, é a probabilidade de a falha ocorrer em um intervalo de tempo $\left[t_{1}, t_{2}\right]$, dado que não ocorreu até $t_{1}$. Em outras palavras, representa as proporções de falhas ocorrendo por unidade de tempo (COLOSIMO; GIOLO, 2006; KECECIOGLU, 2002a). A função taxa de risco pode assumir uma forma (curva) de risco crescente, constante ou decrescente.

Sabe-se que, em seres humanos, e em muitos produtos e componentes, o tempo de vida é uma combinação destas curvas em diferentes períodos de tempo. A Figura 1 ilustra a combinação destas curvas - curva da banheira. Pode-se notar que a curva da banheira possui alta taxa de falha no início de vida (fase mortalidade infantil - prematura), taxa de risco de falha decrescente, um período com taxa de risco de falha relativamente constante (fase de vida útil - maturidade) e um período de desgaste ou velhice (fase de desgaste - mortalidade senil), quando o risco de falha apresenta taxa crescente (CARVALHO, 2012; COLOSIMO; GIOLO, 2006; DHILLON, 2006; EBELING, 1997; KECECIOGLU, 2002a; TOBIAS; TRINDADE, 2011).

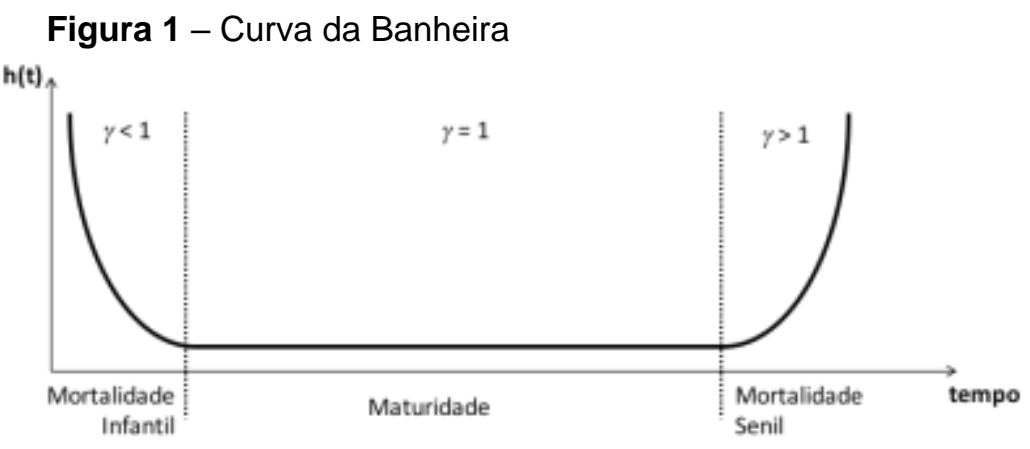

Fonte: Adaptado de Sellitto (2005)

Apesar de algumas distribuições de probabilidade serem, certamente, mais conhecidas, como a Normal e a Binomial, quando se trata de descrever a variável "tempo até a falha", outras distribuições mostram-se mais adequadas. E, embora haja uma variedade de modelos probabilísticos utilizados na análise de confiabilidade, alguns ganham posição de destaque por apresentarem comprovada 
adequação em distintas situações. Pode-se citar os modelos Exponencial, Weibull e Log-normal (COLOSIMO; GIOLO, 2006).

A distribuição de Weibull, amplamente conhecida em virtude de sua simplicidade e flexibilidade em acomodar diferentes formas da função de risco, é talvez o modelo de distribuição mais utilizado em análise de tempos de vida.

A função densidade de probabilidade é dada por:

$$
f(t)=\frac{\gamma}{\theta^{\gamma}} t^{\gamma-1} \exp \left\{-\left(\frac{t}{\theta}\right)^{\gamma}\right\}, \quad t \geq 0
$$

em que $\gamma$ e $\theta$ são, respectivamente, os parâmetros de forma e de escala, ambos positivos.

Para esta distribuição, a função de sobrevivência é dada por:

$$
\mathrm{R}(t)=\exp \left\{-\left(\frac{t}{\theta}\right)^{\gamma}\right\}
$$

e tem taxa de falha igual a:

$$
h(t)=\frac{\gamma}{\theta^{\gamma}} t^{\gamma-1}
$$

onde $t, \gamma, \theta>0$.

Os riscos (taxas de falha) podem ser crescentes quando $\gamma>1$; decrescentes quando $\gamma<1$ e constante quando $\gamma=1$ (neste caso tem-se a distribuição Exponencial).

A expressão para o tempo médio de vida ou esperança matemática denotada por $E(T)$ sob o modelo de Weibull é uma função dos parâmetros $\gamma$ e $\theta$ que inclui o uso da função gama, isto é,

$$
E(T)=\theta \Gamma\left[1+\left(\frac{1}{\gamma}\right)\right]
$$

sendo a função gama $\Gamma(k)$ definida por:

$$
\Gamma(k)=\int_{0}^{\infty} x^{k-1} \exp \{-x\} d x
$$

O percentil $100 p \%$, ou vida residual, é dado por: 


$$
P\left(T \leq t_{p}\right)=t_{p}=\theta[-\ln (1-p)]^{\frac{1}{\gamma}},
$$

em que $p$ é o percentil onde ocorrem as falhas, tp é o provável tempo em que $p \%$ das falhas ocorrerão.

\subsection{Mantenabilidade e Disponibilidade}

A função mantenabilidade $M(t)$ está relacionada com o esforço necessário para a realização da atividade de manutenção, assim, o tempo médio de reparo (MTTR) compreende o tempo gasto para o reparo e para os testes necessários para se colocar o equipamento novamente em operação normal (CERVEIRA; SELLITTO, 2015; MENGUE; SELLITTO, 2013).

A distribuição Log-normal é muito usada em ciências físicas e sociais e em engenharia, neste último caso para descrever o tamanho de partículas, o tempo para haver uma falha no processo (confiabilidade) e o tempo para consertar algo no processo (mantenabilidade).

A função densidade de probabilidade de $T$ é expressa por:

$$
f(t)=\frac{1}{\sqrt{2 \pi t \sigma}} \exp \left\{-\frac{1}{2}\left(\frac{\log (t)-\mu}{\sigma}\right)^{2}\right\}, t>0,
$$

em que $\mu$ é a média do logaritmo do tempo de falha e $\sigma$ o desvio-padrão.

Para a distribuição Log-normal, a função de sobrevivência $R(t)$ é dada por:

$$
\mathrm{R}(t)=\Phi\left(\frac{-\log (t)+\mu}{\sigma}\right)
$$

onde $\Phi(k)$ é a função de distribuição acumulada de uma distribuição normal padrão.

O tempo médio de vida $E(T)$ e a variância $\operatorname{Var}(T)$ são dados, respectivamente, por:

$$
\begin{aligned}
E(T) & =\exp \left\{\mu+\frac{\sigma^{2}}{2}\right\} \\
\operatorname{Var}(T) & =\left\{2 \mu+\sigma^{2}\right\}\left(\exp \left\{\sigma^{2}\right\}-1\right)
\end{aligned}
$$


A disponibilidade $A v(t)$, é a probabilidade de que um equipamento esteja disponível para operação no momento em que este for necessário (MENGUE; SELLITTO, 2013).

Para Dias (2010), a disponibilidade de um equipamento ou sistema está diretamente ligada à sua qualidade temporal, ou seja, a vida útil desse sistema.

Esta dependência é representada pela equação dada em (2.10).

$$
A v(t)=\frac{M T B F}{M T B F+M T T R},
$$

em que:

- MTBF é o Tempo Médio Entre Falhas (Mean Time Between Failures), isto é, a média $E(T)$ do modelo Weibull, dado em (2.4).

- MTTR é o Tempo Médio de Reparo (Mean Time To Repair), isto é, a média $E(T)$ do modelo Log-normal, dado em (2.9).

\subsection{Breve Revisão Sobre Confiabilidade na Formulação de Estratégias de Manutenção Industrial}

A literatura sobre manutenção industrial traz relatos de aplicação de técnicas quantitativas utilizadas na definição e seleção de estratégias de manutenção semelhantes às usadas neste artigo. Dentre muitos outros estudos, alguns podem ser citados por auxiliarem diretamente esta pesquisa.

Sellitto (2005) relata o uso da confiabilidade na formulação de estratégias de manutenção através do estudo de dois casos em fábricas do setor metal-mecânico. Técnicas de modelagem de tempos até a falha e de reparo foram utilizadas para o estabelecimento de estratégias de manutenção a partir do posicionamento dos equipamentos na curva da banheira. Com base nos resultados, o autor estabeleceu condições para o uso da confiabilidade na formulação de estratégias de manutenção em ambos os casos. Além disso, o autor relacionou cada fase do ciclo de vida da curva da banheira com o comportamento da taxa de falha do equipamento, definindo estratégias de manutenção para cada fase.

Sellitto (2007) relata a aplicação da análise estratégica da manutenção em uma linha de produção metal-mecância com base em estudos de confiabilidade sistêmica. Por meio de um estudo de caso descritivo, apresentou e testou um 
método quantitativo e objetivo para a formulação de estratégias de manutenção de equipamentos complexos de produção. A aplicação do método indicou a estratégia de manutenção preventiva para quatro das seis máquinas estudadas, em duas delas de forma pura, em outras duas, de forma combinada com a estratégia preditiva. Com isso, foi possível se calcular intervalos ótimos de intervenção, gerando ganho de escala no serviço e redução do custo de manufatura. Em uma máquina, chegou-se a uma estratégia de manutenção preditiva pura e em outra máquina não se pôde descartar nenhuma das estratégias. Apenas uma das máquinas demandou a estratégia de manutenção corretiva, indicando um ponto frágil na linha de produção quanto ao projeto da máquina ou quanto a aplicação que lhe foi designada no projeto da linha (necessária identificação e correção das fragilidades do projeto).

Mengue e Sellitto (2013) definiram a estratégia de manutenção mais adequada para uma bomba centrífuga instalada em uma planta petrolífera, baseada na modelagem de cálculos de confiabilidade e na definição da posição no ciclo de vida da curva da banheira deste equipamento. O método contribuiu para verificar que a estratégia de manutenção preditiva, utilizada neste equipamento pela empresa, não estava adequada. A modelagem da confiabilidade apontou que o equipamento se encontrava na fase de mortalidade infantil, o que sugeria uma estratégia de manutenção corretiva - objetivando eliminar as reais causas dos possíveis defeitos de fabricação ou de projeto do equipamento.

\section{METODOLOGIA}

O objetivo geral deste trabalho é, com base nos estudos de Sellitto (2005, 2007) e Mengue e Sellitto (2013), avaliar a coerência da atual estratégia de manutenção para os equipamentos produtivos de uma empresa da indústria alimentícia por meio do uso de funções de confiabilidade.

\subsection{Classificação Metodológica}

A pesquisa é de natureza aplicada, pois os resultados serão aplicados na solução de problemas concretos. Quanto ao tipo, a pesquisa é descritiva, objetivando descobrir a frequência com que as falhas nos equipamentos ocorrem, 
sua natureza e características, de forma a identificar se a atual estratégia de manutenção empregada está adequada. Do ponto de vista da abordagem, a pesquisa é quantitativa e, como método, utiliza a modelagem estatística (dos tempos entre falhas - TBF e tempos de reparo - TTR) com o objetivo de obter a confiabilidade de equipamentos de uma empresa da indústria alimentícia.

\subsection{Procedimentos Operacionais}

A Figura 2 ilustra o passo a passo para o desenvolvimento neste estudo. Os procedimentos operacionais são detalhados na seção 4, concomitantemente com a apresentação dos resultados da pesquisa.

Figura 2 - Procedimentos Operacionais

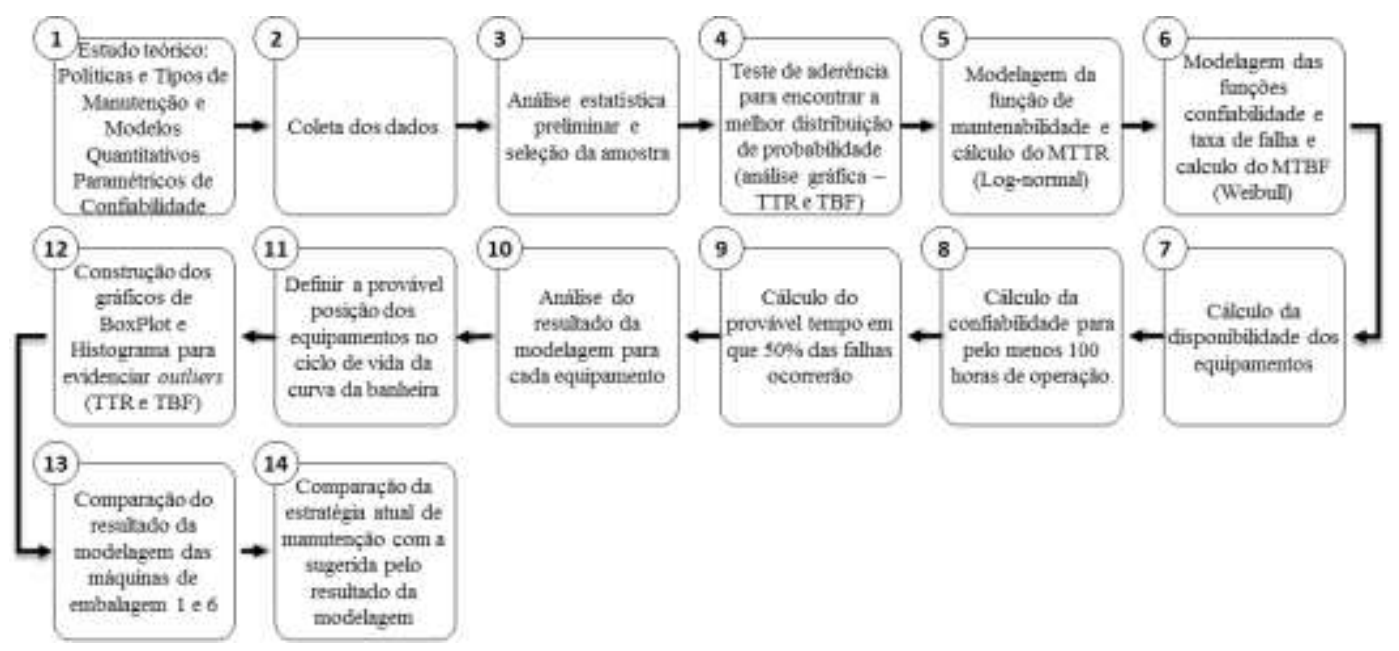

Fonte: Próprio autor

\subsection{Caracterização da Empresa}

A empresa estudada é do ramo de alimentos, segmento de Biscoitos, Torradas e Snacks. Fundada em 1956, atualmente se consolida como a segunda maior fabricante de biscoitos e a primeira marca mais consumida no Brasil. Suas linhas de produtos compõem mais de 100 itens diferentes e seu carro chefe é o tipo Maria/Maisena, do qual, é líder nacional. Sua produção é distribuída no Brasil e em mais de 50 países em todo o mundo

O parque fabril está localizado no interior do Estado de São Paulo e conta com capacidade produtiva de, aproximadamente, 200 mil toneladas de biscoito por 
ano. Com funcionamento de 24 horas por dia, 7 dias por semana, possui 21 linhas de produção em 50 mil $\mathrm{m}^{2}$ de área construída.

Emprega cerca de 3.200 funcionários, 1.662 ligados diretamente ao processo produtivo (aproximadamente 170 funcionários atuam na área de Engenharia de Manutenção).

\section{MODELAGEM ESTATíSticA DA CONFIABILIDADE E ANÁLISE DOS RESULTADOS}

Esta seção apresenta a seleção da amostra de estudo e a construção do modelo de análise de confiabilidade dos dados de acordo com os procedimentos operacionais da Figura 2.

\section{Passo 2 - Coleta dos Dados}

Foram retirados do sistema de gestão da empresa estudada os dados de tempo de reparo TTR (Time-To-Repair) e tempo entre falhas TBF (Time-BetweenFailure) dos equipamentos utilizados no processo produtivo no período entre janeiro de 2014 e maio de 2016.

\section{Passo 3 - Análise Estatística Preliminar e Seleção da Amostra}

Uma análise preliminar dos dados retirados do sistema de gestão da empresa evidencia as linhas de produção com as maiores frequências de falhas.

Pode-se observar na Figura 3 que a Linha 07 de produção apresenta a maior frequência de falhas.

Apesar do complemento da somatória das frequências de falhas em outras linhas de produção ser maior, a Linha 07 é crítica para a empresa, pois funciona 24 horas por dia, 7 dias por semana, parando apenas durante os intervalos de refeições dos operadores e para manutenção preventiva programada. Ela é uma linha dedicada, produzindo apenas biscoitos do tipo Maisena. Tem capacidade para produzir aproximadamente $3.600 \mathrm{~kg} / \mathrm{h}$ de biscoitos e, em geral, opera com $95 \%$ de sua capacidade.

Por ser uma linha de produção muito utilizada, deve apresentar a maior disponibilidade $(A v)$ possível, ou seja, maior tempo médio entre falhas (MTBF), 
menor tempo de reparo (MTTR) e as intervenções não programadas devem ser minimizadas.

Figura 3 - Distribuição de frequência de falhas por linha de produção (período: jan/14 a mai/16)

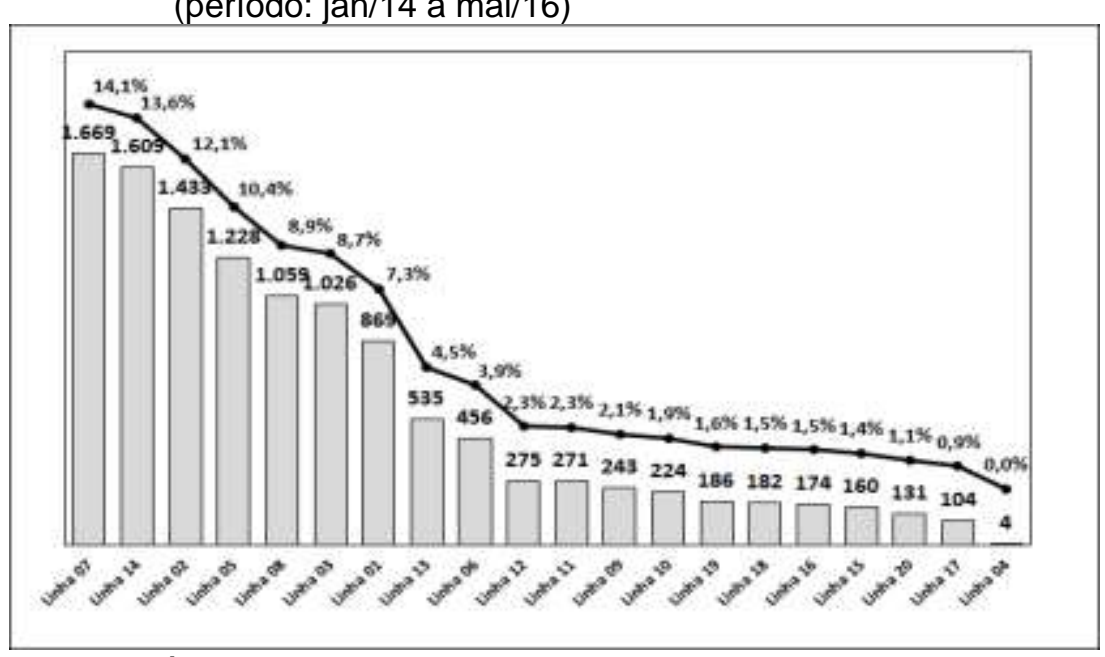

Fonte: Próprio autor

De acordo com o Gerente de Manutenção da fábrica, os equipamentos mais críticos em uma linha de produção de biscoitos são as máquinas de embalagem, uma vez que paradas inesperadas neste ponto interrompem todo o processo anterior. Caso estas paradas sejam suficientemente longas, pode haver deterioração e consequentemente descarte dos produtos (material bruto, material intermediário ou produto final) por se tratar de itens perecíveis.

A Linha 07 de produção possui 8 máquinas de embalagens, 6 utilizadas para a embalagem interna e duas para a embalagem externa dos produtos.

As Máquinas de Embalagem 1, 5, 2 e 6 são da mesma marca/modelo e apresentam capacidade para embalar 80 pacotes por minuto; as Máquinas de Embalagem 3 e 4 (mais antigas) têm capacidade para embalar 40 pacotes por minuto - todas utilizadas para embalagem interna dos produtos. Outras duas máquinas de embalagens são utilizadas para os pacotes externos e têm capacidade para embalar 72 pacotes por minuto (Máquinas de Embalagem SIG2 e SIG1).

A Figura 4 apresenta a distribuição de frequência de falhas dos equipamentos que constituem a Linha 07 de produção. As Máquinas de Embalagem 1, 3, 4, 5, 2 e 6 concentram aproximadamente $82 \%$ das falhas ocorridas nesta linha de produção. 
Figura 4 - Distribuição de frequência de falhas por equipamento - Linha 07

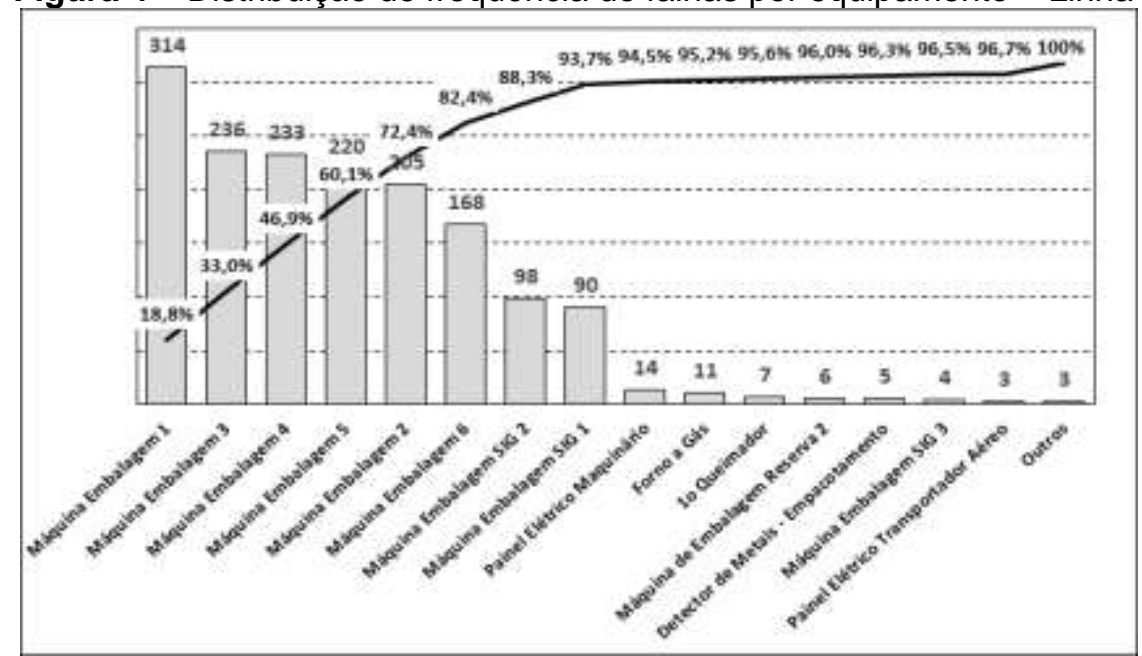

Fonte: Próprio autor

Como as Máquinas de Embalagem SIG2 e SIG1 operam de forma diferente das demais máquinas de embalagem (embalagem externa do produto) e utilizam outro tipo de material (filme plástico), não fazem parte da amostra de estudo. Desse modo, os equipamentos escolhidos como amostra são as Máquinas 1, 3, 4, 5, 2 e 6 da Linha 07 de produção, por apresentarem conjuntamente a maior frequência de falhas.

\section{Passo 4 - Teste de Aderência Para Encontrar a Melhor Distribuição de Probabilidade}

O modelo quantitativo aqui desenvolvido é caracterizado como probabilístico, pois os valores das variáveis de decisão não são conhecidos com certeza. É um modelo paramétrico, no qual se busca a especificação de uma distribuição de probabilidade adequada aos dados.

A análise estatística iniciou-se com o uso de técnicas gráficas para verificação de ajuste dos dados para as distribuições Log-normal, Exponencial, Weibull e Gama para cada equipamento. A estatística de Anderson-Darling (AD) mede o quão bem os dados seguem uma distribuição específica. Em geral, quanto melhor a distribuição se ajusta aos dados, menor o valor da estatística AD.

As hipóteses de nulidade $\left(\mathrm{H}_{0}\right)$ e alternativa $\left(\mathrm{H}_{1}\right)$ para o teste Anderson-Darling são dadas respectivamente, por:

- $\mathrm{H}_{0}$ : os dados seguem uma distribuição específica.

- $\mathrm{H}_{1}$ : os dados não seguem uma distribuição específica. 
Se o valor-p do teste de Anderson-Darling for menor do que o nível de significância escolhido (normalmente $5 \%$ ou $10 \%$ ), conclui-se que os dados não seguem a distribuição especificada. No entanto, o software Minitab® versão 16 nem sempre exibe um valor-p para o teste de Anderson-Darling, pois ele não existe matematicamente para determinados casos.

Quando se está comparando o ajuste de diversas distribuições, a distribuição com o maior valor-p, normalmente, tem o ajuste mais próximo aos dados, mas nem sempre os testes não-paramétricos são sensíveis na discriminação de modelos probabilísticos adequados aos dados. Se as distribuições tiverem valores-p similares, deve-se escolher uma das distribuições com base no conhecimento prático e simplicidade das interpretações. Na prática, uma alternativa muito usada na verificação da adequabilidade de um modelo é o uso de gráficos probabilísticos associados a cada distribuição de probabilidade assumida para os dados (ver Figura $5)$.

Os gráficos probabilísticos dados na Figura 5 e obtidos do software Minitab® versão 16 mostram visualmente a aderência de cada modelo proposto para analisar os tempos de reparo (TTR) das 6 máquinas de embalagem. Os tempos são dados em horas.

A partir da análise gráfica da aderência para os TTR's, foram selecionadas as distribuições com melhor ajuste. No Quadro 1 são apresentadas as distribuições selecionadas a partir dos gráficos probabilísticos dados na Figura 5 para cada máquina de embalagem. No Quadro 1, também são apresentados os valores-p do teste não-paramétrico de Anderson-Darling, que só foi sensível ao ajuste da distribuição Log-normal para os TTR's para a máquina 6 (valor-p $=0,138>0,05$ ). Visualmente, é possível verificar o bom ajuste da distribuição Log-normal para os TTR's das 6 máquinas. 
Figura 5 - Análise gráfica da aderência para o TTR

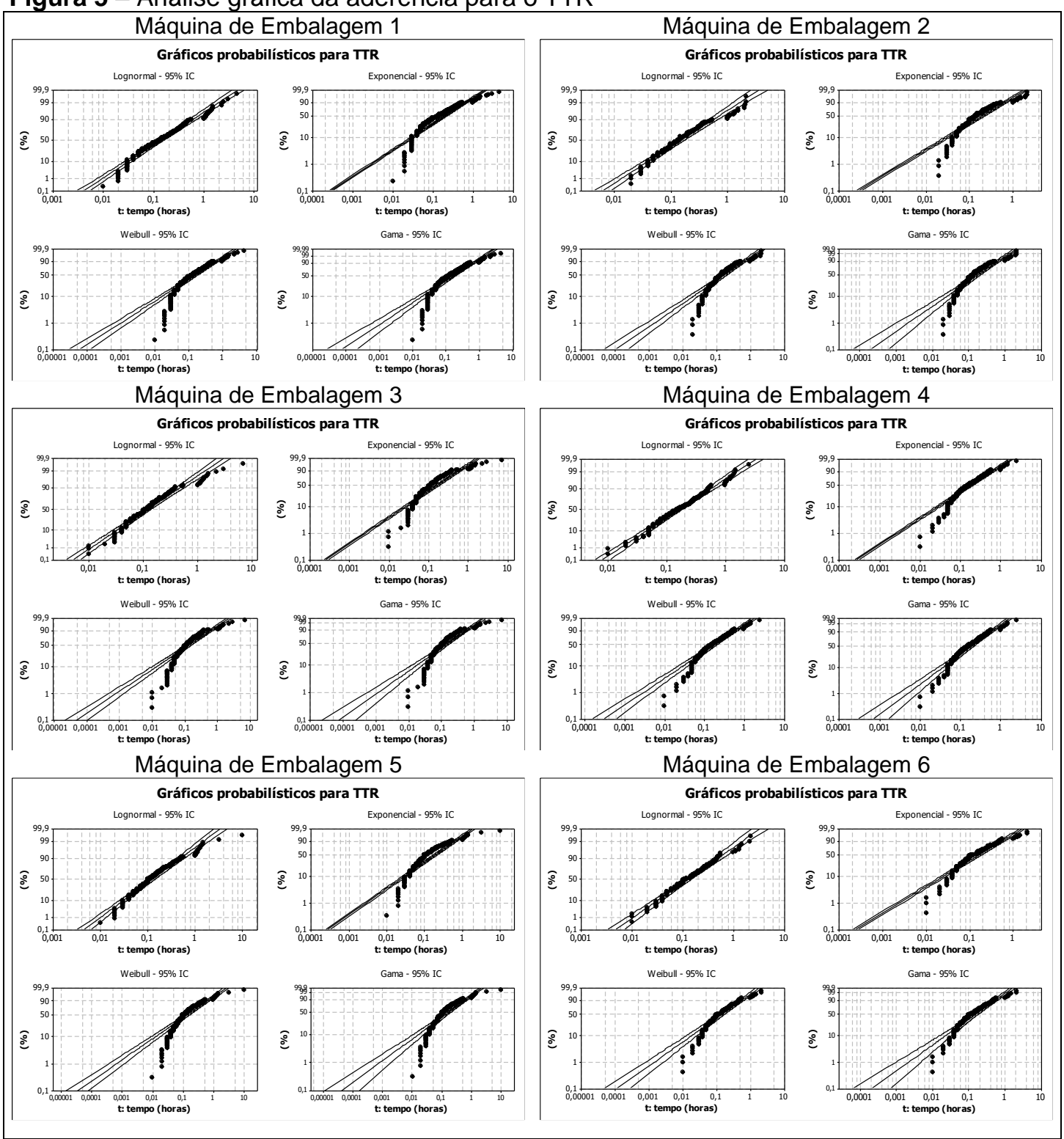

Fonte: Próprio autor

Pela análise gráfica oferecida pelo Minitab ${ }^{\circledR}$ versão 16 , a distribuição de probabilidade do modelo Log-normal parece descrever razoavelmente a amostra dos dados de TTR para o conjunto das 6 máquinas de embalagem.

Em seguida, prosseguiu-se com o uso de técnicas gráficas para verificação de ajuste dos dados para as distribuições consideradas para o tempo entre falhas (TBF).

Os gráficos probabilísticos dados na Figura 6 e também obtidos do software Minitab® versão 16 mostram a aderência de cada modelo proposto para analisar os tempos entre falhas (TBF) das 6 máquinas de embalagem. Os tempos são dados em horas. 
Quadro 1 - Seleção da distribuição com melhor ajuste - TTR (nível de significância: 5\%)

\begin{tabular}{|c|c|c|c|c|}
\hline & \multicolumn{4}{|c|}{ Distribuição } \\
\hline Máquina & Log-normal & Exponencial & Weibull & Gama \\
\hline Máquina 1 & $\begin{array}{l}\text { AD: } 2,005 \\
\text { valor-p: }<0,005 \\
\text { Não rejeitada }\end{array}$ & $\begin{array}{l}\text { AD: } 14,825 \\
\text { valor-p: }<0,003 \\
\text { Rejeitada }\end{array}$ & $\begin{array}{l}\text { AD: } 7,649 \\
\text { valor-p: }<0,010 \\
\text { Rejeitada }\end{array}$ & $\begin{array}{l}\text { AD: } 10,317 \\
\text { valor-p: }<0,005 \\
\text { Rejeitada }\end{array}$ \\
\hline Máquina 2 & $\begin{array}{l}\text { AD: } 1,963 \\
\text { valor-p: }<0,005 \\
\text { Não rejeitada }\end{array}$ & $\begin{array}{l}\text { AD: } 9,905 \\
\text { valor-p: }<0,003 \\
\text { Rejeitada }\end{array}$ & $\begin{array}{l}\text { AD: } 7,771 \\
\text { valor-p: }<0,010 \\
\text { Rejeitada }\end{array}$ & $\begin{array}{l}\text { AD: } 9,321 \\
\text { valor-p: }<0,005 \\
\text { Rejeitada }\end{array}$ \\
\hline Máquina 3 & $\begin{array}{l}\text { AD: } 2,556 \\
\text { valor-p: }<0,005 \\
\text { Não rejeitada }\end{array}$ & $\begin{array}{l}\text { AD: } 16,426 \\
\text { valor-p: }<0,003 \\
\text { Rejeitada }\end{array}$ & $\begin{array}{l}\text { AD: } 11,139 \\
\text { valor-p: }<0,010 \\
\text { Rejeitada }\end{array}$ & $\begin{array}{l}\text { AD: } 13,778 \\
\text { valor-p: }<0,005 \\
\text { Rejeitada }\end{array}$ \\
\hline Máquina 4 & $\begin{array}{l}\text { AD: } 0,771 \\
\text { valor-p: } 0,045 \\
\text { Não rejeitada }\end{array}$ & $\begin{array}{l}\text { AD: } 4,034 \\
\text { valor-p: }<0,003 \\
\text { Rejeitada }\end{array}$ & $\begin{array}{l}\text { AD: } 4,010 \\
\text { valor-p: }<0,010 \\
\text { Rejeitada }\end{array}$ & $\begin{array}{l}\text { AD: } 4,079 \\
\text { valor-p: }<0,005 \\
\text { Rejeitada }\end{array}$ \\
\hline Máquina 5 & $\begin{array}{l}\text { AD: } 1,888 \\
\text { valor-p: }<0,005 \\
\text { Não rejeitada }\end{array}$ & $\begin{array}{l}\text { AD: } 16,820 \\
\text { valor-p: }<0,003 \\
\text { Rejeitada }\end{array}$ & $\begin{array}{l}\text { AD: } 9,089 \\
\text { valor-p: }<0,010 \\
\text { Rejeitada }\end{array}$ & $\begin{array}{l}\text { AD: } 12,054 \\
\text { valor-p: }<0,00 \\
\text { Rejeitada }\end{array}$ \\
\hline Máquina 6 & $\begin{array}{l}\text { AD: } 0,569 \\
\text { valor-p: } 0,138 \\
\text { Não rejeitada }\end{array}$ & $\begin{array}{l}\text { AD: 4,111 } \\
\text { valor-p: }<0,003 \\
\text { Rejeitada }\end{array}$ & $\begin{array}{l}\text { AD: } 3,444 \\
\text { valor-p: }<0,010 \\
\text { Rejeitada }\end{array}$ & $\begin{array}{l}\text { AD: } 4,015 \\
\text { valor-p: }<0,005 \\
\text { Rejeitada }\end{array}$ \\
\hline
\end{tabular}

Fonte: Próprio autor

A partir da análise gráfica da aderência para os TBFs, foram selecionadas as distribuições com melhor ajuste. No Quadro 2 são apresentadas as distribuições selecionadas para cada máquina de embalagem.

No Quadro 2, também são apresentados os valores-p do teste nãoparamétrico de Anderson-Darling para os TBFs para as 6 máquinas na Linha 07. 
Figura 6 - Análise gráfica da aderência para o TBF

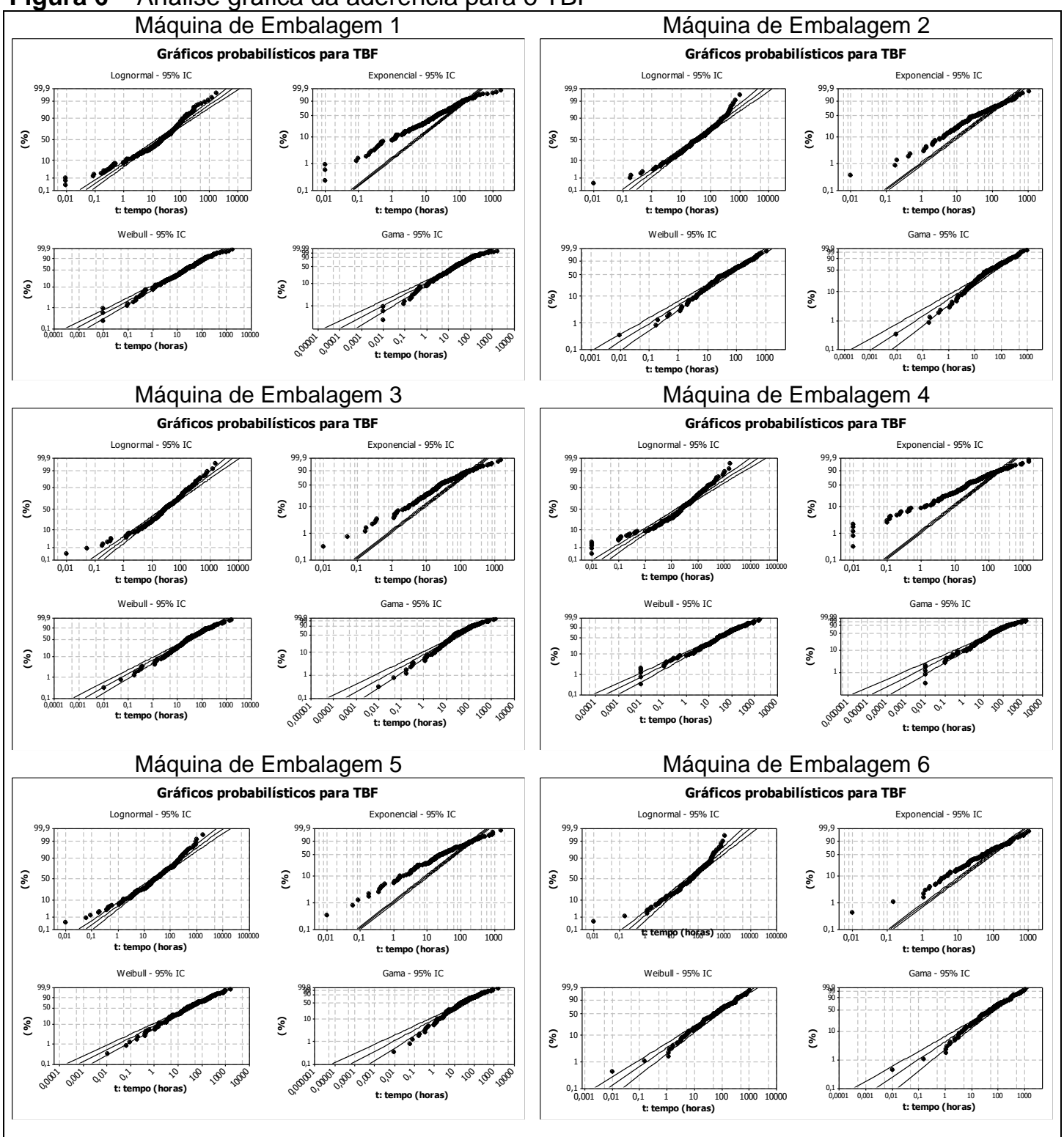

Fonte: Próprio autor

Pela análise gráfica oferecida pelo software Minitab® versão 16, a distribuição de probabilidade do modelo Weibull parece descrever razoavelmente a amostra dos dados de TBF para o conjunto de máquinas. 
Quadro 2 - Seleção da distribuição com melhor ajuste - TBF (nível de significância: 5\%)

\begin{tabular}{|c|c|c|c|c|}
\hline & \multicolumn{4}{|c|}{ Distribuição } \\
\hline Máquina & Log-normal & Exponencial & Weibull & Gama \\
\hline Máquina 1 & $\begin{array}{l}\text { AD: } 4,079 \\
\text { valor-p: }<0,005 \\
\text { Rejeitada }\end{array}$ & $\begin{array}{l}\text { AD: } 33,921 \\
\text { valor-p: }<0,003 \\
\text { Rejeitada }\end{array}$ & $\begin{array}{l}\text { AD: } 0,782 \\
\text { valor-p: } 0,043 \\
\text { Não rejeitada }\end{array}$ & $\begin{array}{l}\text { AD: } 2,750 \\
\text { valor-p: }<0,005 \\
\text { Rejeitada }\end{array}$ \\
\hline Máquina 2 & $\begin{array}{l}\text { AD: } 0,990 \\
\text { valor-p: } 0,013 \\
\text { Rejeitada }\end{array}$ & $\begin{array}{l}\text { AD: } 16,263 \\
\text { valor-p: }<0,003 \\
\text { Rejeitada }\end{array}$ & $\begin{array}{l}\text { AD: } 0,694 \\
\text { valor-p: } 0,072 \\
\text { Não rejeitada }\end{array}$ & $\begin{array}{l}\text { AD: } 1,628 \\
\text { valor-p: }<0,005 \\
\text { Rejeitada }\end{array}$ \\
\hline Máquina 3 & $\begin{array}{l}\text { AD: } 1,647 \\
\text { valor-p: }<0,005 \\
\text { Rejeitada }\end{array}$ & $\begin{array}{l}\text { AD: } 24,853 \\
\text { valor-p: }<0,003 \\
\text { Rejeitada }\end{array}$ & $\begin{array}{l}\text { AD: } 1,479 \\
\text { valor-p: }<0,010 \\
\text { Não rejeitada }\end{array}$ & $\begin{array}{l}\text { AD: } 3,662 \\
\text { valor-p: }<0,005 \\
\text { Rejeitada }\end{array}$ \\
\hline Máquina 4 & $\begin{array}{l}\text { AD: } 3,943 \\
\text { valor-p: }<0,005 \\
\text { Rejeitada }\end{array}$ & $\begin{array}{l}\text { AD: } 42,908 \\
\text { valor-p: }<0,003 \\
\text { Rejeitada }\end{array}$ & $\begin{array}{l}\text { AD: } 0,892 \\
\text { valor-p: } 0,022 \\
\text { Não rejeitada }\end{array}$ & $\begin{array}{l}\text { AD: } 2,912 \\
\text { valor-p: }<0,005 \\
\text { Rejeitada }\end{array}$ \\
\hline Máquina 5 & $\begin{array}{l}\text { AD: } 1,182 \\
\text { valor-p: }<0,005 \\
\text { Rejeitada }\end{array}$ & $\begin{array}{l}\text { AD: } 35,916 \\
\text { valor-p: }<0,003 \\
\text { Rejeitada }\end{array}$ & $\begin{array}{l}\text { AD: } 0,721 \\
\text { valor-p: } 0,061 \\
\text { Não rejeitada }\end{array}$ & $\begin{array}{l}\text { AD: } 2,666 \\
\text { valor-p: }<0,005 \\
\text { Rejeitada }\end{array}$ \\
\hline Máquina 6 & $\begin{array}{l}\text { AD: } 1,349 \\
\text { valor-p: }<0,005 \\
\text { Rejeitada }\end{array}$ & $\begin{array}{l}\text { AD: } 9,506 \\
\text { valor-p: }<0,003 \\
\text { Rejeitada }\end{array}$ & $\begin{array}{l}\text { AD: } 0,401 \\
\text { valor-p: >0,250 } \\
\text { Não rejeitada }\end{array}$ & $\begin{array}{l}\text { AD: } 0,855 \\
\text { valor-p: } 0,037 \\
\text { Rejeitada }\end{array}$ \\
\hline
\end{tabular}

Fonte: Próprio autor

\section{Passo 5 - Modelagem da Função de Mantenabilidade e Cálculo do MTTR}

As funções mantenabilidade do conjunto de máquinas podem ser visualizadas na Figura 7. A modelagem do tempo médio de reparo (MTTR) pelo modelo Lognormal (Estimadores de Máxima Verossimilhança - EMV) e as estatísticas descritivas dos dados são apresentados na Tabela 1.

Dos dados da amostra foram extraídos os valores máximos (Max) e mínimos (Min), média, desvio padrão (DP) e o coeficiente de variação (CV), que mede a variabilidade dos dados.

Figura 7 - Função Mantenabilidade - TTR

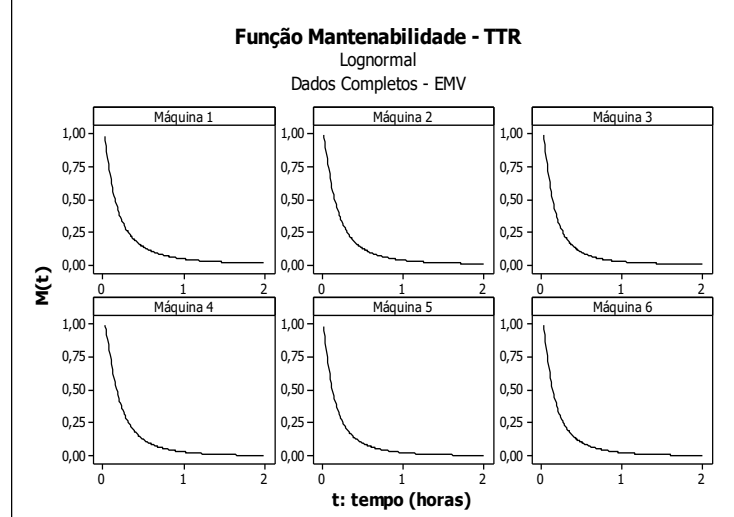

Fonte: Próprio autor 
Tabela 1 - Estatísticas descritivas e EMV dos parâmetros do modelo de TTR - Modelo Log-normal

\begin{tabular}{lcccccccccc}
\hline Máquina & $\mathbf{N}$ & Min & Max & MTTR & DP & CV & IC 95\% & \multicolumn{2}{c}{$\begin{array}{c}\text { Média na } \\
\text { escala log }\end{array} \begin{array}{c}\text { DP na } \\
\text { escala log }\end{array}$} \\
\hline Máquina 1 & 314 & 0,02 & 4,95 & 0,27 & 0,44 & 1,63 & 0,23 até 0,32 & $-1,96$ & 1,14 \\
Máquina 2 & 205 & 0,03 & 2,3 & 0,26 & 0,35 & 1,37 & 0,22 até 0,31 & $-1,88$ & 1,03 \\
Máquina 3 & 236 & 0,02 & 7,2 & 0,21 & 0,29 & 1,37 & 0,18 até 0,25 & $-2,07$ & 1,03 \\
Máquina 4 & 233 & 0,02 & 2,9 & 0,26 & 0,33 & 1,25 & 0,23 até 0,31 & $-1,81$ & 0,97 \\
Máquina 5 & 220 & 0,02 & 10,18 & 0,22 & 0,33 & 1,46 & 0,19 até 0,27 & $-2,07$ & 1,07 \\
Máquina 6 & 168 & 0,02 & 2,32 & 0,23 & 0,32 & 1,43 & 0,19 até 0,28 & $-2,04$ & 1,06 \\
\hline
\end{tabular}

Fonte: Próprio autor

\section{Passo 6 - Modelagem das Funções Confiabilidade e Taxa de Falha e Cálculo do MTBF}

As funções confiabilidade $R(t)$ e taxa de falha $h(t)$ das máquinas de embalagem podem ser visualizadas nos gráficos da Figura 8. A modelagem do tempo médio entre falhas (MTBF) pelo modelo Weibull e a estatística descritiva dos dados são apresentados na Tabela 2.

Figura 8 - Função Confiabilidade e função taxa de falha - TBF
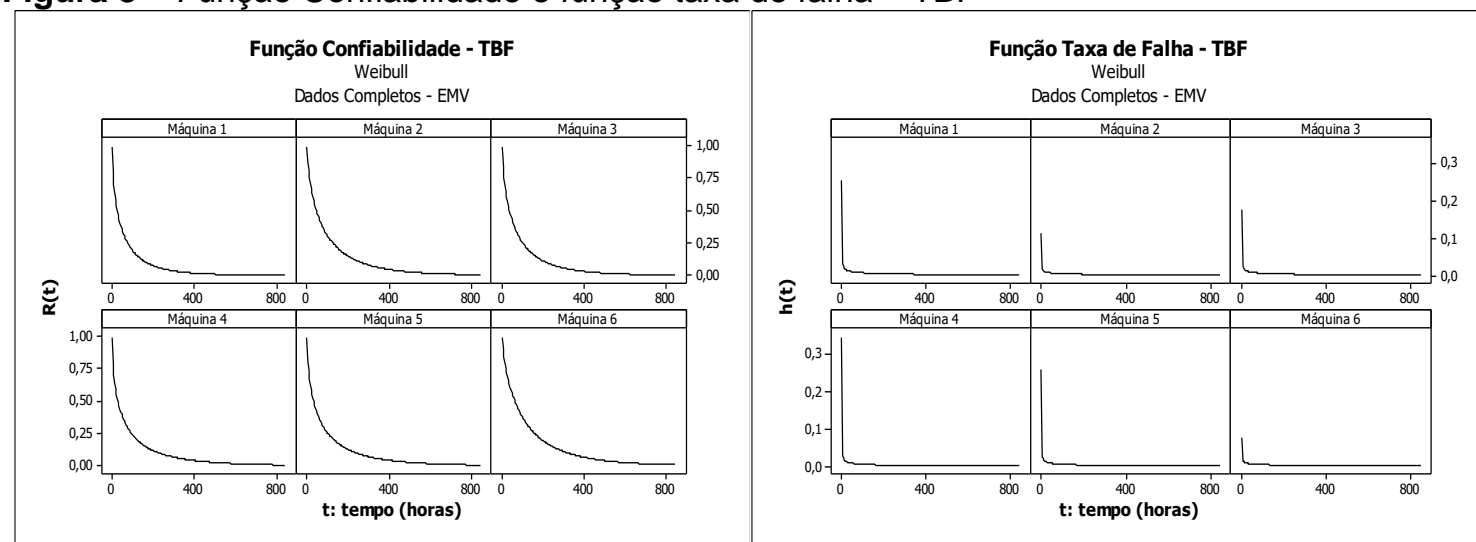

Fonte: Próprio autor

Tabela 2 - Estatísticas descritivas e EMV dos parâmetros do modelo de TBF - Modelo Weibull

\begin{tabular}{lccccccccc}
\hline Máquina & N & Min & Max & MTBF & DP & CV & IC 95\% & \multicolumn{3}{c}{$\begin{array}{c}\text { Parâmetro Parâmetro } \\
\text { de forma } \\
\text { de escala }\end{array}$} \\
\hline Máquina 1 & 313 & 0,02 & $1.794,85$ & 63,34 & 104,37 & 1,65 & 52,94 até 75,78 & 0,63 & 44,94 \\
Máquina 2 & 204 & 0,02 & $1.088,92$ & 101,74 & 150,19 & 1,48 & 83,24 até 124,36 & 0,69 & 79,75 \\
Máquina 3 & 233 & 0,02 & $1.560,27$ & 82,37 & 129,69 & 1,57 & 67,52 até 100,48 & 0,66 & 61 \\
Máquina 4 & 231 & 0,02 & $1.583,47$ & 86,89 & 163,47 & 1,88 & 68,61 até 110,04 & 0,57 & 53,65 \\
Máquina 5 & 219 & 0,02 & $1.683,87$ & 91,48 & 160,47 & 1,75 & 72,90 até 114,81 & 0,6 & 60,95 \\
Máquina 6 & 166 & 0,02 & $1.066,02$ & 125,44 & 176,85 & 1,41 & 101,35 até 155,26 & 0,72 & 102,09 \\
\hline
\end{tabular}

Fonte: Próprio autor

\section{Passo 7 - Cálculo da Disponibilidade dos Equipamentos}

A partir da equação (2.10), foi calculada a disponibilidade das máquinas de embalagem, apresentada na Tabela 3. 
Tabela 3 - Disponibilidade das Máquinas

\begin{tabular}{cccc}
\hline Máquina & MTTR & MTBF & $\begin{array}{c}\text { Dis ponibilidade } \\
\boldsymbol{A} \boldsymbol{v}(\boldsymbol{t})\end{array}$ \\
\hline Máquina 1 & 0,27 & 63,34 & $99,57 \%$ \\
Máquina 2 & 0,26 & 101,74 & $99,75 \%$ \\
Máquina 3 & 0,21 & 82,37 & $99,74 \%$ \\
Máquina 4 & 0,26 & 86,89 & $99,70 \%$ \\
Máquina 5 & 0,22 & 91,48 & $99,76 \%$ \\
Máquina 6 & 0,23 & 125,44 & $99,82 \%$ \\
\hline
\end{tabular}

Fonte: Próprio autor

\section{Passos 8 e 9 - Cálculo da Confiabilidade Para 100 Horas de Operação e Cálculo do Provável Tempo em que 50\% das Falhas Ocorrerão}

Utilizando a equação da função de confiabilidade do modelo Weibull, dada em (2.2), foi calculada a confiabilidade dos equipamentos operarem por pelo menos 100 horas.

Com o uso da equação de percentil de falhas do modelo de Weibull, dada em (2.6), foi calculado o provável tempo, em horas, em que $50 \%$ dos equipamentos apresentarão falha.

Para auxiliar a análise, os resultados dos parâmetros dos modelos Lognormal $(\mu, \sigma)$ e Weibull $(\gamma, \theta)$ e as equações para o cálculo do MTTR, MTBF, confiabilidade, disponibilidade e percentil são resumidas e apresentadas no Quadro 3. 
Quadro 3 - Equações e cálculos da análise de confiabilidade e disponibilidade

\begin{tabular}{|c|c|c|c|c|c|c|c|}
\hline & & \multicolumn{6}{|c|}{ Máquinas de Embalagem } \\
\hline & Parâmetro/Equação & 1 & 2 & 3 & 4 & 5 & 6 \\
\hline $\begin{array}{c}\text { Média } \\
\text { (escala log) }\end{array}$ & $\mu$ & $-1,96$ & $-1,88$ & $-2,07$ & $-1,81$ & $-2,07$ & $-2,04$ \\
\hline $\begin{array}{l}\text { Desvio Padrão } \\
\text { (escala log) }\end{array}$ & $\sigma$ & 1,14 & 1,03 & 1,03 & 0,97 & 1,07 & 1,06 \\
\hline $\begin{array}{c}\text { Forma } \\
\text { (Weibull) }\end{array}$ & $\gamma$ & 0,63 & 0,69 & 0,66 & 0,57 & 0,6 & 0,72 \\
\hline $\begin{array}{c}\text { Escala } \\
\text { (Weibull) }\end{array}$ & $\theta$ & 44,94 & 79,75 & 61 & 53,65 & 60,95 & 102,09 \\
\hline $\begin{array}{l}\text { MTTR } \\
\text { (horas) }\end{array}$ & MTTR $=\exp \left(\mu+\frac{\sigma^{2}}{2}\right)$ & 0,27 & 0,26 & 0,21 & 0,26 & 0,22 & 0,23 \\
\hline $\begin{array}{l}\text { MTBF } \\
\text { (horas) }\end{array}$ & $\begin{array}{l}\text { MTBF }=\theta * \Gamma\left(1+\frac{1}{\gamma}\right) \\
\Gamma \text { é a função gama }\end{array}$ & 63 & 102 & 82 & 87 & 91 & 125 \\
\hline Disponibilidade & $A v=\frac{M T B F}{M T B F+M T T R}$ & $99,57 \%$ & $99,75 \%$ & $99,74 \%$ & $99,70 \%$ & $99,76 \%$ & $99,82 \%$ \\
\hline $\begin{array}{c}\text { Confiabilidade } \\
\mathrm{t}=100 \mathrm{~h}\end{array}$ & $R(t)=e^{\left[-\left(\frac{t}{\theta}\right)^{v}\right]}$ & $19,04 \%$ & $31,03 \%$ & $25,07 \%$ & $24,05 \%$ & $26,01 \%$ & $37,34 \%$ \\
\hline $\begin{array}{l}50 \% \text { das falhas } \\
\text { (p50\%) }\end{array}$ & $P\left(T \leq t_{v}\right)=t_{v}=\theta[-\ln (1-p)]^{\frac{1}{v}}$ & 25 & 47 & 35 & 28 & 33 & 61 \\
\hline
\end{tabular}

Fonte: Próprio autor

\section{Passo 10 - Análise dos Resultados da Modelagem Para Cada Equipamento}

Neste passo faz-se a análise dos resultados da modelagem dos dados para o tempo de reparo, tempo entre falhas, disponibilidade e confiabilidade para cada máquina de embalagem apresentados nas Tabelas 1, 2 e 3, sob a luz dos trabalhos de Sellitto $(2005,2007)$ e Mengue e Sellitto (2013).

Neste trabalho, assim como em Sellitto (2005), Mengue e Sellitto (2013), Mobley (2008) entre outros, a estratégia de manutenção corretiva é assumida como corretiva planejada, diferenciando-se da corretiva de emergência.

O que se propõe com a estratégia de manutenção corretiva é a busca e correção das falhas de origem, ou seja, a estratégia não se limita a corrigir a falha o mais rápido possível, mas sim, a encontrar e eliminar a causa raiz das falhas.

A Máquina de Embalagem 1 apresenta tempo médio de reparo de 16,2 minutos (MTTR $=0,27$ horas), sendo o maior entre o conjunto de equipamentos. Com tempo médio entre falhas (MTBF) igual a 63 horas, o menor entre o conjunto e, com parâmetro de forma $(\gamma)$ igual a 0,63 , pode-se inferir que a taxa de falhas é decrescente e que o equipamento se encontra na fase de mortalidade infantil da curva da banheira, uma vez que $\gamma<1$. O maior tempo médio de reparo (MTTR) e o 
menor tempo médio entre falhas (MTBF) contribuíram para que a Máquina de Embalagem 1 apresente a menor disponibilidade entre o conjunto de máquinas, estando disponível para a operação em $99,57 \%$ do tempo. Para o modelo de Weibull, dado um tempo $t$ qualquer, por exemplo, $t=100$ horas, tem-se que a confiabilidade da Máquina 1 funcionar ao menos 100 horas é de aproximadamente 19,04\%, (menor confiabilidade entre o conjunto de máquinas), ou seja, $80,96 \%$ de probabilidade de falhar antes deste tempo e, $50 \%$ de probabilidade das falhas ocorrem em até de 25 horas de funcionamento (o menor tempo entre o conjunto de máquinas).

A Máquina de Embalagem 2 apresenta tempo médio de reparo (MTTR) de 15,5 minutos (0,26 horas) e tempo médio entre falhas (MTBF) de 102 horas, o segundo maior tempo. O resultado do parâmetro de forma do modelo de Weibull indica taxa de falha decrescente $(\gamma=0,69)$, o que sugere que o equipamento se encontra na fase de mortalidade infantil da curva da banheira, uma vez que $\gamma<1$. A Máquina de Embalagem 2 esteve disponível para operação em 99,75\% do tempo. Dado um tempo $t=100$ horas, a confiabilidade da máquina funcionar ao menos 100 horas é de aproximadamente $31,03 \%$, ou seja, existe probabilidade de $68,97 \%$ de a máquina não funcionar até este tempo. Aproximadamente $50 \%$ das falhas ocorrerão em até 47 horas de operação.

A Máquina de Embalagem 3 apresenta tempo médio de reparo de 12,9 minutos (MTTR = 0,21 horas), o menor tempo entre o conjunto de máquinas. $O$ tempo médio entre falhas é de 82 horas (MTBF $=82)$. O parâmetro de forma $(\gamma)$ do modelo Weibull é igual a 0,66 indicando taxa de falha decrescente, pois este é menor que 1, posicionando o equipamento na fase de mortalidade infantil da curva da banheira. Em 99,74\% do tempo o equipamento esteve disponível para operação. A probabilidade deste equipamento funcionar até um tempo $t=100$ horas é de aproximadamente $25,07 \%$ (74,93\% de probabilidade de falhar antes deste tempo e $50 \%$ de chance das falhas ocorrem antes de 35 horas de funcionamento).

A Máquina de Embalagem 4 apresenta tempo médio de reparo de 15,8 minutos (MTTR = 0,26 horas) e tempo médio entre falhas de 87 horas (MTBF $=87$ ). Com $\gamma=0,57$ (parâmetro de forma de Weibull) pode-se inferir que o equipamento apresenta taxa de falha decrescente e, como $\gamma<1$, pode-se posicionar 0 equipamento na fase de mortalidade infantil curva da banheira. A Máquina de 
Embalagem 4 esteve disponível para operação em 99,70\% do tempo. De acordo com o modelo de Weibull, dado um tempo $t=100$ horas, a confiabilidade da Máquina 4 funcionar por pelo menos 100 horas é de aproximadamente 24,05\% (75,95\% de probabilidade de falhar até este tempo e $50 \%$ de chance das falhas ocorrem antes de 28 horas em funcionamento).

A Máquina de Embalagem 5 apresenta tempo médio de reparo de 13,4 minutos (MTTR = 0,22 horas). O tempo médio entre falhas (MTBF) é de 91 horas. $O$ parâmetro de forma do modelo Weibull é de 0,60 o que indica que o equipamento se encontra na fase de mortalidade infantil $(\gamma<1)$ da curva da banheira, com taxa de falha decrescente. A Máquina de Embalagem 5 apresenta disponibilidade para a operação de $99,76 \%$ do tempo. Para um tempo $t=100$ horas, a confiabilidade do equipamento permanecer funcionando por pelo menos até este tempo é de $26,01 \%$ (73,99\% de probabilidade de falhar antes disso e $50 \%$ de chance das falhas ocorrem antes de 33 horas de operação).

A Máquina de Embalagem 6 apresenta tempo médio de reparo (MTTR) de 13,6 minutos (0,23 horas) e tempo médio entre falhas (MTBF) de 125, o maior entre o conjunto de máquinas. Assim como as demais máquinas, apresenta parâmetro de forma $<1(\gamma=0,72)$, apresentando taxa de falha decrescente e também pode ser posicionada na fase de mortalidade infantil da curva da banheira. A Máquina de Embalagem 6 é o equipamento com a maior disponibilidade entre o conjunto de máquinas, estando disponível para a operação em $99,82 \%$ do tempo. Dado um tempo $t=100$ horas, a confiabilidade da máquina funcionar por pelo menos este tempo é de aproximadamente $37,34 \%$ (equipamento com a maior confiabilidade entre o conjunto de máquinas). Apresenta $50 \%$ de probabilidade das falhas ocorrem antes de 61 horas de funcionamento, o maior tempo entre o conjunto de máquinas.

\section{Passo 11 - Definição da Provável Posição dos Equipamentos no Ciclo de Vida da Curva da Banheira}

A curva da banheira representa genericamente a função de risco $h(t)$ ao longo do ciclo de vida dos equipamentos (CERVEIRA; SELLITTO, 2015).

Obteve-se, pelo modelo Weibull, parâmetro de forma $\gamma<1$ para todas as máquinas, o que remete à taxas de falhas decrescentes. Desse modo, o conjunto das 6 máquinas de embalagens estudadas se encontram na fase de mortalidade 
infantil. Nesta fase, ocorrem as falhas prematuras causadas principalmente por má especificação, mau projeto, má instalação ou por má qualidade na fabricação de componentes de reposição.

Na Figura 9 é apresentada a provável posição das máquinas na curva da banheira.

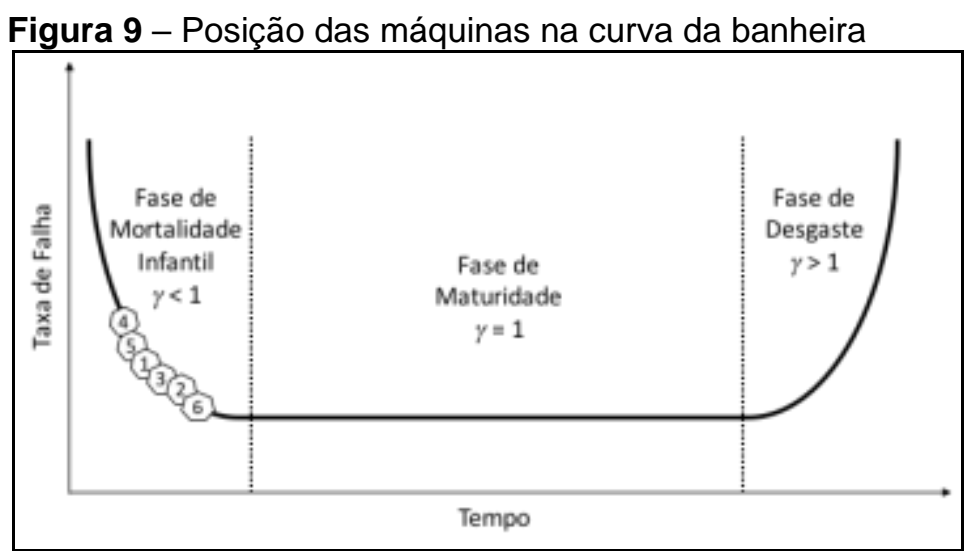

Fonte: Dados da pesquisa. Adaptado de Sellitto (2005)

\section{Passo 12 - Construção dos Gráficos de BoxPlot e Histograma para Evidenciar Outliers}

Os coeficientes de variação (CV) para o tempo de reparo (TTR) e tempo entre falhas, (TBF) apresentados nas Tabelas 1 e 2, respectivamente, demonstram alta variação nestes tempos ( $C V>1$ ), o que pode ser comprovado a partir das faixas dos intervalos de confiança (IC 95\%) para os tempos.

Isso ocorre porque estes tempos apresentam outliers (observações com valores extremos, muito distantes das médias), conforme os box-plots da Figura 10. Os histogramas da Figuras 11 apresentam a concentração do tempo de reparo e tempo entre falhas nos períodos iniciais da linha do tempo.

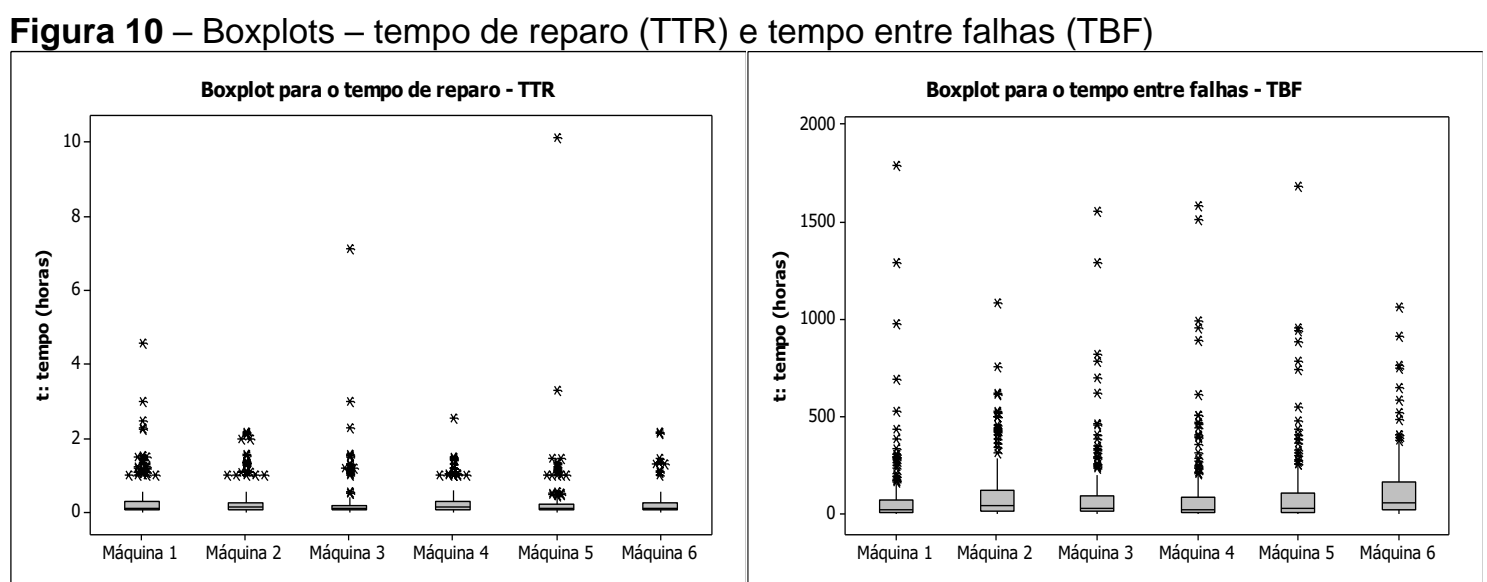

Fonte: Próprio autor 
Figura 11 - Histogramas - tempo de reparo (TTR) e tempo entre falhas (TBF)
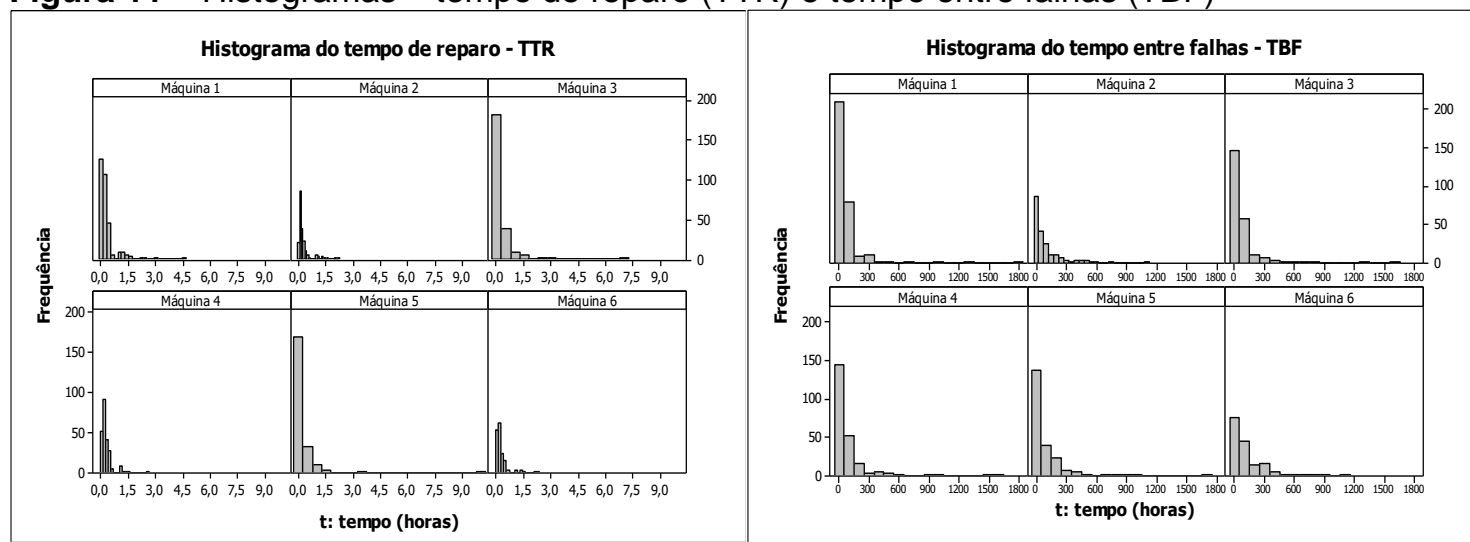

Fonte: Próprio autor

\section{DISCUSSÃO}

Esta seção discute como os resultados da pesquisa podem ser utilizados na definição de estratégias de manutenção para os equipamentos da empresa estudada.

\section{Passo 13 - Comparação do Resultado da Modelagem das Máquinas de Embalagem 1 e 6}

Como mencionado na seção 4.2, as máquinas de embalagem 1, 2, 5 e 6 são do mesmo modelo e operam sob as mesmas condições, no entanto, os resultados da modelagem de confiabilidade destes equipamentos foram bastante diferentes.

Pode-se destacar a Máquina de Embalagem 1 em função desta ser 0 equipamento que apresenta os piores indicadores entre o conjunto de máquinas estudado. Maior tempo médio de reparo, menor tempo médio entre falhas, menor disponibilidade operacional, menor confiabilidade e menor tempo onde $50 \%$ das falhas ocorrem. Foi também o equipamento que apresentou o maior número de falhas no período estudado, conforme Figura 4, foram 314 falhas no período (18,8\% do total e apresenta $33,05 \%$ mais falhas que a Máquina de Embalagem 3, a segunda em quantidade de falhas). Assim como os demais equipamentos, esta pôde ser posicionada na fase de mortalidade infantil da curva da banheira, já que apresenta parâmetro de forma $(\gamma)$ menor que 1 , de acordo com o modelo Weibull, ou seja, apresenta taxa de risco decrescente ao longo do tempo.

Já a Máquina de Embalagem 6 é o único equipamento onde o parâmetro de forma do modelo Weibull é mais próximo a $1(\gamma=0,72)$, indicando uma possível 
transição para a fase de maturidade da curva da banheira. Mengue e Sellitto (2013) argumentam que a migração do equipamento ao longo da curva da banheira em direção à fase de maturidade é um indicador de sucesso das ações de manutenção.

A Máquina de Embalagem 6 é também o equipamento que apresenta os melhores indicadores ente o conjunto de máquinas estudado. Conjuntamente com a Máquina de Embalagem 3, são os únicos equipamentos a ultrapassarem as 100 horas de funcionamento médio entre as falhas (MTBF). Seu tempo médio de reparo (MTTR) é o terceiro melhor do conjunto estudado. Apresenta também a maior disponibilidade, além de maior confiabilidade de funcionamento para um tempo $t=$ 100 horas e maior tempo em que $50 \%$ das falhas ocorrerão.

$O$ registro dos dados de paradas de máquinas no banco de dados da empresa carece de detalhamento sobre informações acerca do tipo de falha ocasionada (modos de falhas), pois, como o campo para o registro é de texto livre, não há padronização na descrição da causa da parada, além da falta de dados detalhados sobre os manutentores, dificultando assim um entendimento mais aprofundado das falhas de origem.

Autores como Sellitto (2005), Mengue e Sellitto (2013), Diedrich e Sellitto (2014), Machado e Andrade (2013), Cerveira e Sellitto (2015), entre outros, apontam para a importância da quantidade e qualidade do registro dos dados das atividades de manutenção para se desenvolver modelos que melhor descrevam o sistema estudado.

A falta de padronização no registro dos modos de falha inviabilizou um estudo mais aprofundado para se identificar quais fatores influenciaram para que a Máquina de Embalagem 1 apresentasse os piores indicadores, comparados com os indicadores da Máquina de Embalagem 6.

\section{Passo 14 - Comparação da Estratégia Atual vs. Estratégia Indicada Pela Pesquisa}

A engenharia de Manutenção da empresa adota a estratégia de manutenção preventiva periódica mesclada com a estratégia preventiva condicionada ao estado dos componentes.

As manutenções preventivas são executadas 1 vez por mês e a troca de componentes é feita somente se o estado destes apresentar sinais de desgastes, 
fadiga ou deterioração e, as falhas entre manutenções preventivas, são removidas através de reparações mínimas. Além disso, a estratégia de manutenção é a mesma para todos os equipamentos da linha de produção e as atividades de manutenção são executadas pela mesma equipe de manutentores. Nenhuma análise quantitativa dos dados de falhas dos equipamentos é utilizada para a definição da estratégia de manutenção dos equipamentos.

Para Kardec e Nascif (2009) a estratégia de manutenção preventiva programada é adequada para equipamentos que apresentam ciclo de vida descrito pela curva da banheira, se estes forem equipamentos mais simples e os padrões de falha com a idade de desgaste forem identificáveis.

Para Moubray (1997) se um determinado equipamento não possui um modo predominante e característico de falha, revisões programadas podem pouco contribuir para aumentar a confiabilidade e, neste caso, a estratégia de manutenção preventiva é pouco eficaz.

Desta forma, como os modos de falhas dos equipamentos estudados não são registrados da forma mais adequada e não puderam ser identificados e, os respectivos equipamentos são um sistema complexo, pode-se inferir que a definição da atual estratégia de manutenção preventiva para os equipamentos não é a mais coerente, pois é necessário conhecer o comportamento das falhas dos equipamentos a fim de se planejar e gerenciar melhor a definição de estratégias de manutenção.

Além disso, a escolha da estratégia de manutenção preventiva para equipamentos que se encontram na fase de mortalidade infantil da curva da banheira pode implicar na perpetuidade do equipamento nesta fase, pois acaba-se trocando os componentes que não apresentam falha de origem (SELLITTO, 2005).

Como os resultados da modelagem da pesquisa demonstram que todos os equipamentos estudados se encontram na fase de mortalidade infantil da curva da banheira, novamente a definição da atual estratégia de manutenção preventiva não é a mais coerente para os equipamentos, devendo a empresa definir uma estratégia de manutenção corretiva com o objetivo de se identificar e eliminar as falhas de origem (que nesta fase podem ser ocasionadas devido a mau projeto, má instalação, má fabricação de componentes sobressalentes ou má operação). Porém, Santos e Sellitto (2016) alertam que a adoção da estratégia de manutenção corretiva com o 
objetivo de se eliminar as causas de origem pode implicar em altos investimentos e longos tempos de indisponibilidade para reformas e melhorias que eliminem as falhas estruturais detectadas.

Kardec e Nascif (2009) apontam que a taxa de mortalidade infantil será tanto maior quanto pior for o trabalho desenvolvido nas fases que antecedem a entrada em operação de qualquer equipamento ou sistema, tendo como consequências a baixa confiabilidade e lucros cessantes para a planta.

Desse modo, a empresa objeto de estudo deveria adotar como estratégia mais coerente para o conjunto das 6 máquinas de embalagem a manutenção corretiva, para que além de reparar o sistema o mais rápido possível, sejam corrigidos os erros de concepções, pois há a probabilidade de existirem erros de projeto, má instalação ou má operação, ocasionando a mortalidade infantil.

A empresa estudada deve, também, adotar a metodologia da Manutenção Centrada na Confiabilidade (RCM), de modo que o setor de Engenharia de Manutenção possa desempenhar sua função estratégica de manter os equipamentos disponíveis para operação pelo maior tempo possível, reduzindo a probabilidade de paradas não planejadas.

Verifica-se, com este estudo, que as estratégias de manutenção necessitam ser questionadas a todo o momento, além de serem aplicadas de acordo com a taxa de falha dos equipamentos ou modos de falhas.

No Quadro 4 são apresentadas algumas sugestões de melhorias para a definição de estratégias de manutenção para a empresa objeto de estudo. 
Quadro 4-Sugestões de Melhorias

\begin{tabular}{|c|c|}
\hline Sugestão & Ação \\
\hline 1 & $\begin{array}{l}\text { Adoção da estratégia de manutenção corretiva para os equipamentos estudados, nã } \\
\text { necessariamente abandonando a estratégia de manutenção preventiva; }\end{array}$ \\
\hline 2 & $\begin{array}{l}\text { Aquisição de um sistema de gestão da manutenção que gerencie dados mais detalhados } \\
\text { e padronizados das ações de manutenção; }\end{array}$ \\
\hline 3 & $\begin{array}{l}\text { Na impossibilidade de aquisição de um novo sistema de gestão da manutenção, sugere- } \\
\text { se a realização de melhorias no atual sistema, de modo que este possa melhor gerenciar } \\
\text { os dados de modos de falha e dados dos manutentores; }\end{array}$ \\
\hline 4 & $\begin{array}{l}\text { Adoção de estratégia de manutenção para os equipamentos com base na análise de } \\
\text { confiabilidade, considerando comportamento da curva de falhas, especificidades e } \\
\text { peculiaridades de cada equipamento e, no limite, de cada modo de falha; }\end{array}$ \\
\hline 5 & A contratação ou formação de um especialista em análise de confiabilidade; \\
\hline 6 & $\begin{array}{l}\text { Adoção da metodologia da Manutenção Centrada na Confiabilidade (RCM), de modo que } \\
\text { a Engenharia de Manutenção esteja dotada de ferramentas e métodos estruturados } \\
\text { (qualitativos e quantitativos) que auxiliem a adoção de estratégias de manutenção que } \\
\text { garantam uma abordagem ótima para redução de gastos financeiros e custo total do ciclo } \\
\text { de vida de equipamentos. }\end{array}$ \\
\hline
\end{tabular}

Fonte: Próprio autor

\section{CONCLUSÕES}

O objetivo geral deste trabalho foi avaliar a coerência da definição da atual estratégia de manutenção para os equipamentos produtivos de uma empresa da indústria alimentícia por meio do uso de funções de confiabilidade. A modelagem dos tempos entre falhas (TBF) e tempos de reparo (TTR) foi a principal técnica de pesquisa utilizada neste trabalho.

Os dados foram originados do histórico de paradas, registrados e gerenciados pela Engenharia de Manutenção da empresa estudada.

Percebe-se a importância de se ter o registro destas informações feito com qualidade, para que o desenvolvimento de estudos deste tipo de atividade possa trazer resultados confiáveis aos gestores da manutenção de equipamentos, possibilitando a inferência e decisão correta de ações que proporcionem melhor eficiência e competitividade para a empresa.

A principal conclusão é que, dado o parâmetro de forma calculado, todos equipamentos encontram-se na fase de mortalidade infantil do ciclo de vida da curva da banheira.

Uma das características da fase de mortalidade infantil é que existem problemas originados no projeto, na especificação ou na instalação do equipamento. Assim, tais problemas devem ser resolvidos antes que se formule uma estratégia de manutenção preventiva com trocas programadas, pois não se tem certeza que 
simples substituições por itens equivalentes irão resolver os problemas de quebras. Muitas vezes, estes itens sobressalentes podem ser até mais fracos, devido a variabilidade na fabricação.

Como a atual estratégia de manutenção empregada pela empresa é a manutenção preventiva e os equipamentos estão na fase de mortalidade infantil, existe a probabilidade de que a atividade de manutenção esteja trocando justamente os componentes fortes, pois ainda não falharam.

Assim, os resultados obtidos respondem à questão de pesquisa, demonstrando que a estratégia de manutenção preventiva definida atualmente para os equipamentos não é coerente para a posição que estes se encontram na curva da banheira. Uma vez que os equipamentos se encontram na fase de mortalidade infantil, a manutenção corretiva (com o objetivo de buscar e eliminar as causas de origem) seria a mais adequada.

A consequência da não realização da manutenção corretiva é a permanência dos equipamentos na fase de mortalidade infantil, impossibilitando estes de entrarem na região de maturidade ou vida útil do equipamento (SELLITTO, 2005).

A principal contribuição do artigo é a sugestão da adoção da estratégia de manutenção corretiva para os equipamentos, não necessariamente abandonando a estratégia de manutenção preventiva.

Por fim, a análise de confiabilidade mostrou-se ser uma ferramenta robusta de auxílio aos tomadores de decisão na atividade de definição de estratégias de manutenção mais adequadas para os equipamentos.

\section{Trabalhos futuros}

Como trabalho futuro, sugere-se o estudo da confiabilidade qualitativa dos modos de falha de cada equipamento, com o objetivo de se entender como as falhas ocorrem.

Sugere-se ainda, a replicação deste estudo em outras linhas de produção da planta que apresentam altas frequências de falhas (conforme aponta a Figura 3), de forma a aumentar a confiabilidade dos equipamentos por meio de estratégias adequadas de manutenção, além de identificar possíveis fatores comuns de ocorrência de falhas que afetam a competitividade da empresa. 


\section{AGRADECIMENTOS}

Os autores agradecem o Conselho Nacional de Desenvolvimento Científico e Tecnológico (CNPq) e a Fundação Nacional de Desenvolvimento do Ensino Superior Particular (FUNADESP).

\section{REFERÊNCIAS}

CARVALHO, M.T.B. Análise e avaliação de períodos de inspeção em sistemas de natureza tecnológica. Tese (Doutorado em Engenharia Industrial e de Sistemas) Universidade do Minho - Escola de Engenharia. 267 p., Guimarães, Portugal, 2012.

CERVEIRA, D.S; SELLITTO, M.A. Manutenção centrada em confiabilidade (MCC): análise quantitativa de um forno elétrico a indução. Produção Online, v. 15, n. 2, p. 405-432, 2015. DOI: http://dx.doi.org/10.14488/1676-1901.v15i2.1615

COLOSIMO, E.A; GIOLO, S.R. Análise de Sobrevivência Aplicada. São Paulo. Blucher, 2006.

DHILLON, B.S. Maintainability, Maintenance, and Reliability for Engineers. Taylor \& Francis Group. 2006.

DIAS, A. Confiabilidade na manutenção industrial, 2010. http://docplayer.com.br/3238650-Confiabilidade-na-manutencao-industrial.html, acessado em: 27/mai/2016.

DIEDRICH, A.; SELLITTO, M.A. Manutenção centrada em confiabilidade - estudo de caso na indústria de bebidas, Revista Eletrônica Produção em Foco, v. 4, n. 1, 2014.

DOI: http://dx.doi.org/10.14521/P2237-5163.2014.0005.0006

EBELING, C.E. An Introduction to Reliability and Maintainability Engineering. McGrawHill Companies. 1997.

FARRERO, J.C.; TARRÉS, L.G.; LOSILLA, C.B. Optimization of replacement stocks using a maintenance programme derived from reliability studies of production systems. Industrial Management \& Data Systems, v. 102, n. 4, p. 188-196, 2002.

DOI: https://doi.org/10.1108/02635570210423226

IRESON, W.G; COOMBS, C.F; MOSS, R.Y. Handbook of Reliability Engineering and Management. $2^{\mathrm{a}}$ edição. McGraw-Hill, 1995.

KARDEC, A.; NASCIF, J. Manutenção: função estratégica. 3a edição. Rio de Janeiro. Qualitymark: Petrobras, 2009.

KECECIOGLU, D. Reliability Engineering Handbook, Volume 1. DEStech Publications, 2002a.

KLUTKE, G.A.; KIESSLER, P.C.; WORTMAN, M.A. A critical look at the bathtub curve. IEEE Transactions on Reliability, v. 52, n. 1, 2003.

DOI: http://dx.doi.org/10.1109/TR.2002.804492 
MACHADO, F; ANDRADE, J.J.O. Emprego da confiabilidade para o estabelecimento de estratégias de manutenção na indústria metal-mecânica. XXXIII Encontro Nacional De Engenharia de Produção, ENEGEP. 2013.

MENDES, A.A.; RIBEIRO, J.L.D. Um estudo do suporte quantitativo necessário para a operacionalização da MCC. Prod., São Paulo, v. 21, n. 4, p. 583-593, 2011.

DOI: $\underline{\text { http://dx.doi.org/10.1590/S0103-65132011005000032 }}$

MENDES, A.A.; RIBEIRO, J.L.D. Estabelecimento de um plano de manutenção baseado em análises quantitativas no contexto da MCC em um cenário de produção JIT. Production, v. 24, n. 3, p. 675-686, july/sept, 2014.

DOI: http://dx.doi.org/10.1590/S0103-65132013005000065

MENGUE, D.C; SELLITTO, M.A. Estratégia de manutenção baseada em funções de confiabilidade para uma bomba centrífuga petrolífera. Revista Produção Online, v. 13, n. 2, p. 759-783, 2013. DOI: http://dx.doi.org/10.14488/1676-1901.v13i2.1341

MOBLEY, R. Keith. Maintenance Engineering Handbook. 7ª edição. McGrawHill, 2008.

MOUBRAY, J. Reliability-Centered Maintenance. Industrial Press. New York, 1997.

RAPOSO, C. Overall equipment effectiveness: aplicação em uma empesa do setor de bebidas do polo industrial de Manaus. Revista Produção Online, v. 11, n. 3, p. 648-667. 2011. DOI: http://dx.doi.org/10.14488/1676-1901.v11i3.529

RAUSAND, M. Reliability centered maintenance. Reliability Engineering and System Safety, v. 60, n. 2, p. 121-133. 1998. DOI: https://doi.org/10.1016/S0951-8320(98)83005-6

RAUSAND, M; OIEN, K. The basic concepts of failure analysis. Reliability Engineering and System Safety, v.53, p. 73-83. 1996. DOI: https://doi.org/10.1016/0951-8320(96)00010-5

SANTOS, N.A; SELLITTO, M.A. Estratégia de manutenção e aumento da disponibilidade de um posto de compressão de gases na indústria petrolífera. Revista Produção Online, v. 16, n. 1, p. 77-103, jan/mar 2016. DOI: http://dx.doi.org/10.14488/1676-1901.v16i1.1905

SELLITTO, M.A; BORCHARDT, M; ARAUJO, D.R.C. Manutenção centrada em confiabilidade: aplicando uma abordagem quantitativa. XXII Encontro Nacional de Engenharia de Produção, ENEGEP. 2002.

SELLITTO, M.A. Formulação estratégica da manutenção industrial com base na confiabilidade dos equipamentos. Revista Produção, v. 15, n. 1, p. 44-59, jan/abr 2005. DOI: http://dx.doi.org/10.1590/S0103-65132005000100005

SELLITO, M.A. Análise estratégica da manutenção de uma linha de fabricação metalmecânica baseada em cálculos de confiabilidade de equipamentos. Gepros: Gestão da Produção, Operações e Sistemas, v. 2, n. 2, p. 97, 2007.

TOBIAS, P.A; TRINDADE, D.C. Applied Reliability. 3th edition. Taylor \& Francis Group, 2011.

VACCARO, G.L.R. Modelagem e análise da confiabilidade de sistemas. Dissertação (Mestrado em Engenharia de Produção) - Universidade Federal do Rio Grande do Sul. 222 p. Rio Grande do Sul, 1997. 
VAZ, J.C. Manutenção de sistemas produtivos: um estudo sobre a gestão da disponibilidade de equipamentos. Dissertação (Mestrado em Engenharia de Produção) Escola Politécnica da Universidade de São Paulo. 203 p. São Paulo, 2003.

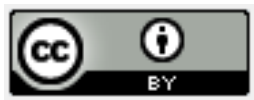

Artigo recebido em 12/05/2017 e aceito para publicação em 10/10/2017

DOI: http://dx.doi.org/10.14488/1676-1901.v18i2.2871 